\title{
Optimized design of RC deep beams based on performance metrics applied to strut and tie model and in-plane stress conditions
}

\author{
D. P. Santos ${ }^{\mathrm{a}^{*}}$
}

\section{J. A. D. Fernandes Neto ${ }^{a}$}

\section{Reginato ${ }^{a}$}

\section{R. Carrazedo ${ }^{a}$}

a Departamento de Engenharia de Estruturas, Escola de Engenharia de São Carlos, Universidade de São Paulo. Av. Trabalhador São-carlense 400, São Carlos, SP, Brasil. E-mails: danilopereira.eng@usp.br, anchietafernandes@usp.br, luanreginato@usp.br, carrazedo@usp.br.

* Corresponding author

http://dx.doi.org/10.1590/1679-78255633

\begin{abstract}
Deep beams do not behave according to classical beam theory. The nonlinearity of strain distribution within these elements requires application of strut and tie models (STM) or other alternatives to evaluate the complex stress field. Although the design of these elements is a common task for structural engineers, limited research is found on assessing effectiveness of the results. The purpose of this work is to compare, in a systematic approach, different design solutions for a deep beam using selected performance metrics which are strain energy, reinforcement ratio, maximum load, structural efficiency, safety factor and cracking behavior. A deep beam ( $2.85 \mathrm{~m}$ of height, $4.20 \mathrm{~m}$ of length and $0.2 \mathrm{~m}$ of thickness) with a square opening $(0.7 \mathrm{~m} \times 0.7 \mathrm{~m})$ close to one of the supports was subjected to a uniform loading at the top surface while resting on supports at both ends. A simplified finite element model (FEM) of this beam was developed simulating concrete with elastic linear stress-strain behavior and disregarding steel reinforcements. This model allowed determination of elastic stress fields necessary to subsequent analyses. Four STM were then developed, supposing the total load respectively represented by one (STM-1), two (STM-2), four (STM-4) or eight (STM8) concentrated loads equally spaced along the top of the beam. Additionally, an in-plane stress field method (SFM) was applied to the design of the same beam subjected to uniform loading on the top surface. After design and detailing of the reinforcement for each situation, nonlinear FEMs were used to predict the ultimate conditions. The strain energy reduced significantly comparing results from STM-1 to STM-2 and subsequently to STM- 4 and remained at a low level in STM- 8 and SFM. The reinforcement ratio reduced systematically from STM-1 to STM-8, was minimum with the SFM and the same behavior was followed by maximum load. The structural efficiency (maximum load/reinforcement ratio) increased from STM-1 to STM-8, with maximum efficiency at STM-8 and was slightly below with SFM. The safety factor reduced systematically from STM- 1 to STM-8 and was slightly lower with SFM, but in all cases was above acceptable limits found in design codes.
\end{abstract}

\section{Keywords}

Deep beam; strut and tie model; reinforced concrete; finite element model; nonlinear analysis.

\section{INTRODUCTION}

Design of reinforced concrete elements frequently relies on Euler-Bernoulli kinematic hypothesis, which admits a linear strain distribution along the cross-section of the structural elements. Regions obeying this hypothesis are known as " $B$ " regions. However, there are several situations of interest where this hypothesis is no longer valid due to 
discontinuity in geometry or load configuration, such as pile caps, corbels, footings, beam column connections, deep beams and elements with openings. These regions are classified as " $\mathrm{D}$ " regions and require special design methods such as Strut and Tie Models (STM) or Stress Field Method (SFM).

The Strut and Tie Model is attributed to Schlaich et al. (1987) and is based on discretization of the structure in compression (struts) and tension (ties) bars connected by nodes. The forces in this truss can be easily evaluated, allowing verification of concrete stresses and determination of steel reinforcement areas. They suggest that the geometry of the model can be based on elastic stress fields, and the design made following the theory of plasticity. The verification of serviceability can be carried out with the same model used for limit state analyses.

Structural elements such as the deep beam are commonly used in elevated reservoirs, supporting beams in buildings, concrete curtain walls, and elements subjected to actions distributed in their plane are also considered as $D$ regions and evaluated in a singular way (Silva \& Giongo, 2000). According to different codes, deep beams are defined by their relation between the span and the height $(I / h)$, assuming values of $I / h \leq 4$ according to ACl 318-14 (American Concrete Institute 2014), and $I / h \leq 3$ in codes such as EC2 - Eurocode 2 (British Standards Institution 2004), and ABNT NBR 6118 (Associação Brasileira De Normas Técnicas 2014).

Besides the specific treatment due to the own discontinuity conditions, it is often necessary to create openings for the accommodation of electric, hydraulic or air-conditioned services and accessories (Hawileh et al., 2012). The insertion of these openings causes an increase in stress concentrations and reduces the shear strength of the deep beams due to the interruption of the natural path of the loads to the support (Ibrahim et al., 2018). Given these situations, authors such as Hussain and Pimanmas (2016), Qazi et al. (2015), Dhahir (2018), Moradi and Esfahani (2017) and Hawileh et al. (2012) used materials reinforced with steel fibers and fiber-reinforced carbon polymers to evaluate various possibilities of strengthening in the critical regions, and to investigate their influence on the cracking behavior of some structural elements.

Despite the existence of refined techniques such as the Finite Element Method (FEM), Micro Truss (MTM) and Stringer-Panel (SPM) (Mello \& Souza, 2016; Vieira, 2018), international codes such as ACI 318-14 (2014), EC2 (2004) and ABNT NBR 6118 (2014) still recommend the use of struts and ties model (STM) to solve this problem. Zhong et al. (2017) defines the STM as a visual representation to indicate the internal forces in a discrete way, idealizing the load flow through compressed members (struts), traction and the intersection between them (nodes). Currently, the STM for the design of concrete deep beams is idealized through the evaluation of the elastic stress field by finite elements (Najafian \& Vollum, 2013).

Recently, due to the difficulties in the analysis of these elements, Almeida et al. (2013), Hardjasaputra (2015) and Herranz et al. (2012) presented structural models applied to the STM obtained through topological evaluation with the objective of optimizing the structural components. However, the need for computational implementation and the search for advanced numerical solutions make it difficult to apply this technique in typical projects. Moreover, most of the published works use simplified and conservative models for STM, obtained from the discretization of the load into a single concentrated load, an unusual situation in the applications of deep beams.

From the discussion above, the present research focused on providing simple and reliable solutions for deep beams with discontinuities subjected to distributed loading using five structural models, with four types derived from STM and the last one evaluated according to the in-plane stress conditions. Based on a nonlinear numerical analysis, load capacity results are also presented for comparison and determination of structural safety. In this way, all the models were evaluated from six performance metrics: factor of safety, reinforcement ratio, structural efficiency, maximum load, cracking behavior and the minimum energy strain, allowed to determine with precision the effectiveness of each model.

\section{ANALYSIS AND SIZING METHODOLOGY}

\subsection{Strut and tie model}

Since the beginning of 20th century, from researches by W. Ritter and E. Mörsch, truss analogy has been used in design and verification of reinforced concrete structures (Silva and Giongo, 2000). At the beginning this approach was focused on the effect of shear force, however Marti (1985) applied an arrangement of struts, ties and nodes also for the calculation of longitudinal reinforcement of a beam. Afterwards, Schlaich et al. (1987) expanded the concepts to evaluate the discontinuity conditions of other structural elements and Liang et al. (2000) proposed an evolutionary topology optimization method applied to automatic developing optimal strut and tie models in reinforced concrete structures.

Although the classic model dates to the 1980s, and normative codes like EC2 (2004) also present a methodology with the application of FEM, the STM continues to be applied in numerous current scientific works such as El-Sayed 
(2014), Lim and Hwang (2016) and Dhahir (2018). Therefore, it is of practical and academic interest to discuss the propositions, analysis and optimization of STM.

According to Herranz et al. (2012), the design of the STM should comply with three recommendations: (i) to comply with static equilibrium, (ii) to have enough strength in ties, struts and nodes, and (iii) to be an isostatic model. It is important to emphasize that this last recommendation is not mandatory, but aims at simplifying the calculation of forces, so it is possible to propose indeterminate models such as those studied by Kim \& Yun (2011).

In general, the normative codes focus on the verification of strength in struts, ties and nodes, so the way the model is created is the sole responsibility of the designer. In the next sections, recommendations of $\mathrm{ACl} 318-14$, EC2 (2004) and ABNT NBR 6118:2014 will be presented.

\subsubsection{Struts verification}

The verification of struts depends on the concrete strength and the width assigned to them. The determination of concrete strength is influenced by the state of stresses in the evaluated region, especially because of cracking. The width of strut depends on its anchoring conditions, which vary with the reinforcement position, loading application and/or other overlapping struts (Silva \& Giongo, 2000).

The EC2 (2004) proposes only two expressions for the calculation of concrete strength in the struts region ( $\left.\sigma_{R d, m a x}\right)$. The first expression is restricted to the struts subjected only to compression. The second expression must be used when there is tensile stress transverse to the strut. This expression is also reproduced by other codes for the struts crossed by two or more ties. These equations are described below, where $f_{c k}$ is the characteristic compressive strength of concrete, and $f_{c d}$ is its design value.

$$
\begin{aligned}
& \sigma_{R d, \text { max }}=f_{c d} \\
& \sigma_{R d, \text { max }}=0.6\left(1-\frac{f_{c k}}{250}\right) f_{c d}
\end{aligned}
$$

As indicated in $\mathrm{ACl} 318-14$, the geometry of the struts can be determined through Figure 1. In this way, it is possible to increase the struts width by arranging the reinforcements in several layers and/or increasing the region of load application.

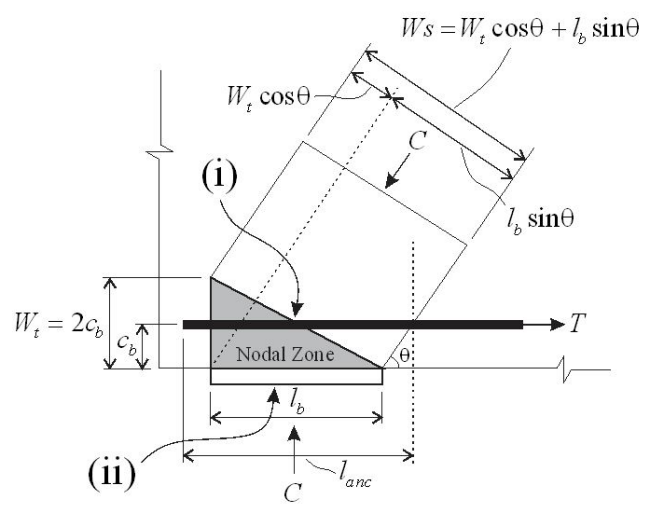

Figure 1: Struts width based on nodes region (adapted from $\mathrm{ACl}$ 318-14).

In the development of this paper, the determination of the struts geometry was based on both the summary description of $\mathrm{ACl} 318-14$ and the linear elastic analysis produced from the finite element models. It is important to note that the maximum angles of the inclined struts $\left(0^{\circ}<\theta<90^{\circ}\right)$ obeyed the requirement of ABNT NBR 6118:2014, $0.57<$ $\tan \theta \leq 2.0$.

\subsubsection{Sizing of ties}

According to ACl 318-14 and ABNT NBR 6118:2014, the area of steel reinforcement can be calculated through Equation (3), in which $F_{s d}$ is the tensile force assigned to the tie. The arrangement of the tie bars must be representative 
in the proposed STM and be well anchored in the nodal regions. Therefore, the adoption of smaller diameter bars and the arrangement in the form of stirrups are good solutions for the improvement of anchoring conditions.

$A_{s}=\frac{F_{S d}}{f_{y d}}$

Anchoring can be ensured by determining a minimum perimeter of reinforcement arriving at the node. This perimeter is calculated as a function of four parameters: the available anchorage length, the ratio of the calculated and effective steel area, the force in the tie and the concrete strength. The minimum perimeter can still be reduced by the use of hooks; however, in this paper, the anchoring conditions are guaranteed using fasteners, since the adoption of the minimum perimeter modifies the total steel area, which could jeopardize comparison between the evaluated models.

\subsubsection{Nodal regions verification}

The European, Brazilian and US standards evaluate the stress state present in the nodal region for the definition of the compressive strength of concrete. Following the proposition made by Schlaich et al. (1987), the three standards use the concepts of CCC, CCT and CTT nodes illustrated in Figure 2.

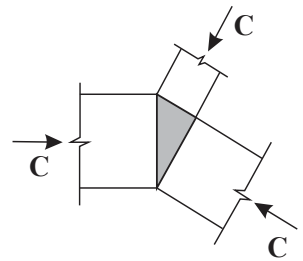

a)

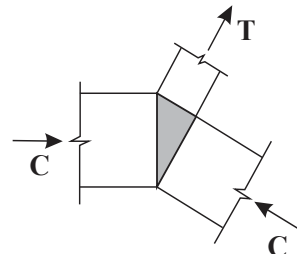

b)

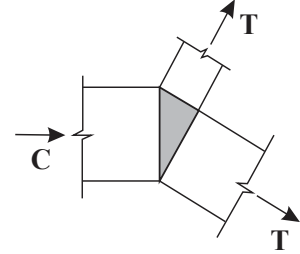

c)

Figure 2: Nodal zones: (a) CCC-Node, (b) CCT-Node, (c) CTT-Node.

In general, the compressive strength of concrete is penalized by the presence of tensile stresses. Table 1 summarizes the requirements of EC2 (2004) and ABNT NBR6118: 2014.

Table 1: Parameters of nodal strength for European and Brazilian standards.

\begin{tabular}{cccc}
\hline & \multicolumn{3}{c}{ Strength of nodal zones $\left(\boldsymbol{\sigma}_{\text {Rd, } \max }\right)$} \\
\hline CCC-Node & CCT-Node & CTT-Node \\
EC 2 (2004) & $1.0 \cdot\left(1-f_{c k} / 250\right) f_{c k} / 1.5$ & $0.85 \cdot\left(1-f_{c k} / 250\right) f_{c k} / 1.5$ & $0.85 \cdot\left(1-f_{c k} / 250\right) f_{c k} / 1.5$ \\
NBR6118:2014 & $0.85 \cdot\left(1-f_{c k} / 250\right) f_{c k} / 1.4$ & $0.72 \cdot\left(1-f_{c k} / 250\right) f_{c k} / 1.4$ & $0.60 \cdot\left(1-f_{c k} / 250\right) f_{c k} / 1.4$ \\
\hline
\end{tabular}

After determining the concrete strength, the geometries of nodal regions must be defined in order to calculate the resistant nodal force, $\sigma_{R d, \max } A_{\text {node }}$, which will be compared to the highest force on the node. For the determination of the nodal geometry, the $\mathrm{ACl} 318-14$ prescribes the definition of an area $\left(A_{\text {node }}\right)$ by means of which force acting on the strut or tie arrives at the node. The $A_{\text {node }}$ is calculated by the product between the thickness of the structural element and the smaller length of the nodal face with acting forces. In Figure 1 the two possible faces for $A_{\text {node }}$ were highlighted with indices (i) and (ii).

\subsection{Expressions for in-plane stress conditions}

Annex F of EC2 (2004) provides the parameters necessary for the calculation, the provision of the reinforcement and the verification of the compressed concrete regions from a finite element analysis of a 2D model. This approach will be used to determine the fourth deep beam solution evaluated in this paper.

\subsubsection{Basic concepts of EC2 Annex F}

For the development of the expressions it is useful to visualize a plane structure in reinforced concrete with reinforcement bars. In this way, the vertical and horizontal reinforcements are considered to react to the tensile stresses in these two directions ( $\sigma_{E d x}$ and $\sigma_{E d y}$ ), whereas the diagonal concrete struts only react to the compressive stresses $\left(\sigma_{c}\right)$. Finally, the $\tau_{E d x y}$ represents the shear stresses that must be resisted by the concrete. 


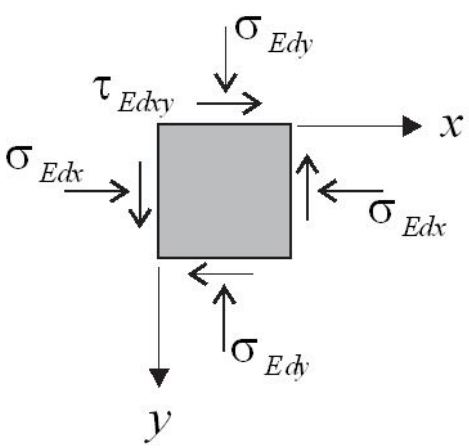

a)

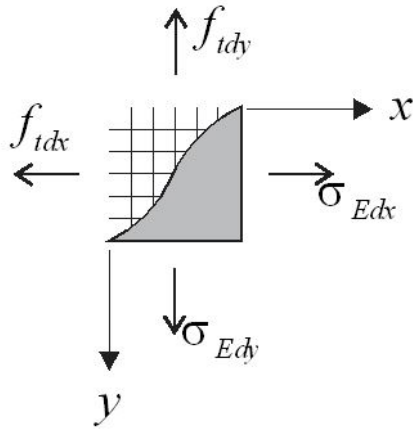

b)

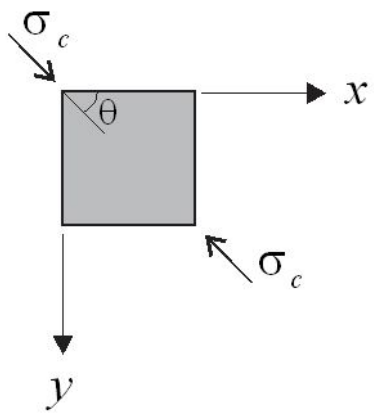

c)

Figure 3: (a) In-plane stress on an element, (b) resistance from ties $\left(f_{t d x}\right.$ e $\left.f_{t d y}\right)$, (c) stress action in concrete $\left(\sigma_{c}\right)$.

The design equations are developed for ULS (Ultimate Limit State), so the stress acting on the reinforcement bars will be the yield stress $\left(f_{y d}\right)$. However, since steel occupies only a percentage of the element area, the resisted stress will be a percentage of $f_{y d}$, that is $\rho_{x} f_{y d}$ and $\rho_{y} f_{y d}$ for each direction. This concept can be verified in Equations (4) and (5), prescribed by EC2 (2004) and detailed by Blaauwendraad (2010).

$f_{t d x}=\rho_{x} f_{y d}$

$f_{t d y}=\rho_{y} f_{y d}$

Thus, as $f_{t d x}$ and $f_{t d y}$ are calculated from the in-plane stress conditions (Section 2.2.2) it is possible to obtain the geometric reinforcement ratio $\left(\rho_{x} e \rho_{y}\right)$ which is sufficient for the determination of the reinforcements.

\subsubsection{Sizing algorithm for in-plane stress}

First of all, it is necessary that the compression stresses are considered positive and $\sigma_{E d x}>\sigma_{E d y}$. Next, the reinforcement sizing is made, knowing that the EC2 does not require reinforcement when $\sigma_{E d x}$ and $\sigma_{E d y}$ are compression stresses and $\sigma_{E d x} . \sigma_{E d y}>\tau_{E d x y}$.

If reinforcement is necessary, Eurocode 2 provides general equations for the determination of the reinforcements and concrete strengths. It is added that these equations can be developed from the equilibrium equations applied to the elements of Figure 3, given the consideration that concrete does not provide tensile strength. In addition to these general equations, EC2 (2004) establishes Equations (6) and (7) for an optimized angle of struts $\left(\theta= \pm 45^{\circ}\right)$.

$\sigma_{E d x} \leq\left|\tau_{E d x y}\right| \rightarrow\left\{\begin{array}{l}f_{t d x}^{\prime}=\left|\tau_{E d x y}\right|-\sigma_{E d x} \\ f_{t d y}^{\prime}=\left|\tau_{E d x y}\right|-\sigma_{E d y} \\ \sigma_{c d}=2\left|\tau_{E d x y}\right|\end{array}\right.$

$\sigma_{E d x}>\left|\tau_{E d x y}\right| \rightarrow\left\{\begin{array}{l}f_{t d x}^{\prime}=0 \\ f_{t d y}^{\prime \prime}=\tau_{E d x y}^{2} / \sigma_{E d x}-\sigma_{E d y} \\ \sigma_{c d}=\sigma_{E d x}\left(1+\left(\tau_{E d x y} / \sigma_{E d x}\right)^{2}\right)\end{array}\right.$

The flowchart in Figure 4 illustrates the main steps of the sizing algorithm that applies to the equations described above. 


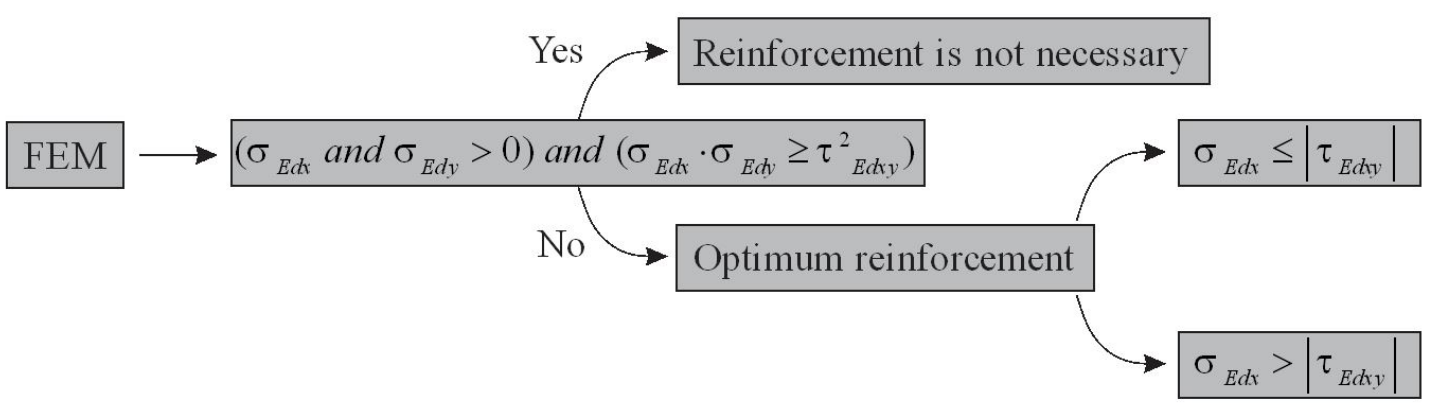

Figure 4: Flowchart for the sizing of ties through EC2 (2004).

Furthermore, it is necessary to assure that all concrete is verified for their safety. This verification is done with Equations ( 8 ) and (9) that ensure the concrete integrity to the compression and shear forces, respectively.

$$
\begin{aligned}
& \sigma_{c} \leq 0.6\left(1-\frac{f_{c k}}{250}\right) f_{c d} \\
& \left|\tau_{E d x y}\right| \leq \frac{1}{2}\left[0.6\left(1-\frac{f_{c k}}{250}\right) f_{c d}\right]
\end{aligned}
$$

\subsection{Minimum energy strain criterion}

The minimum energy strain criterion applied in this paper was postulated by Schlaich et al. (1987), Equation (10), based on the principle of minimum strain energy for linear elastic behavior of struts and ties after cracking, where $F_{i}$ represents the force on an element (strut or tie), $l_{i}$ is the length of the element and $\varepsilon_{i}$ is its mean strain.

$\sum F_{i} \cdot l_{i} \cdot \varepsilon_{i}=$ Minimum

As presented by Schlaich et al. (1987), this analysis is only necessary for the ties, since the strain in the struts and consequently the work done by them is much lower. It was through this criterion that the models studied were compared in terms of optimization. It is added that this criterion was not applied to the truss models proposed, but to the nonlinear models studied in this paper.

\subsection{Factor of safety}

The safety verification for the models studied was carried out using the methodology proposed in 1994 by Joaquim Figueiras that defines an alternative way to evaluate the safety in reinforced concrete structures from a nonlinear numerical analysis (Pimentel, 2004; Souza and Bittencourt, 2006). In this methodology the structural element is dimensioned for a characteristic load $\left(P_{k}\right)$ from a linear analysis, considering the nonlinearity of the materials. Then the maximum load $\left(P_{u}\right)$ is determined from a numerical model, and the factor of safety $\left(\lambda_{u}=P_{u} / P_{k}\right)$ is calculated. The Figure 5 summarizes this process.

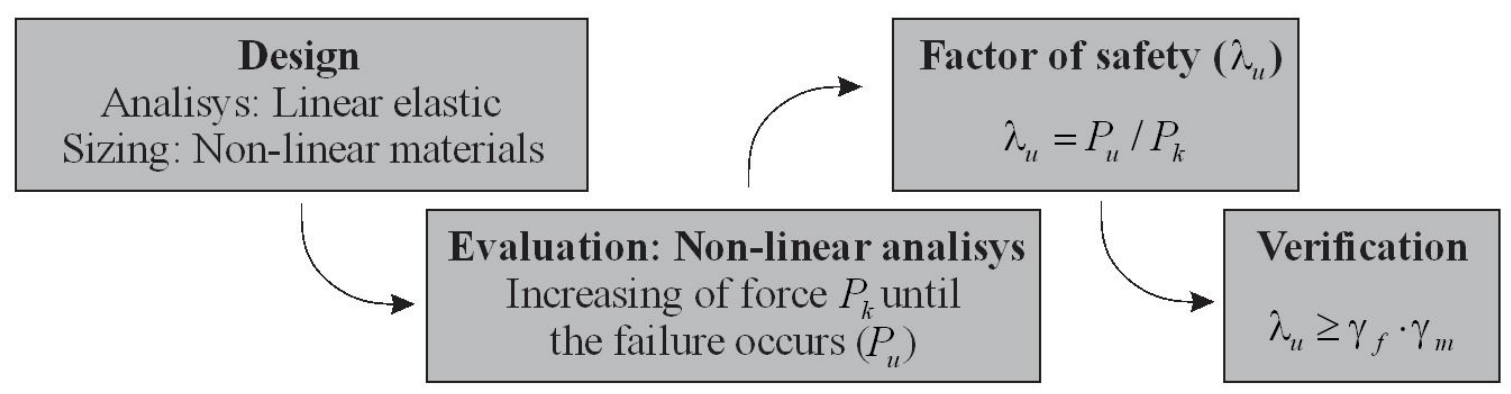

Figure 5: Factor of safety calculation flowchart. 
The structure will be considered secure when $\lambda_{u} \geq \gamma_{f} . \gamma_{m}$, where $\gamma_{f}$ is the partial factor applied to increase the internal forces and $\gamma_{m}$ is the strength reduction factor of the material in which the failure occurred. Several values for the factor $\lambda_{u}$ can be obtained according to the applied technical standard. Table 2 summarizes some results for international codes.

Table 2: Values calculated for $\lambda_{u}$ from partial factors extracted from international codes.

\begin{tabular}{cll}
\hline & Concrete failure & Steel failure \\
\hline CSA-A23.3 (2014) & $\lambda_{u}=\gamma_{f} \cdot \gamma_{m}=1.4 \cdot 1.54=2.16$ & $\lambda_{u}=\gamma_{f} \cdot \gamma_{m}=1.4 \cdot 1.18=1.65$ \\
$\begin{array}{c}\text { EC2 (2004) and Model Code (Fédération } \\
\text { Internationale du Béton 2010) }\end{array}$ & $\lambda_{u}=\gamma_{f} \cdot \gamma_{m}=1.35 \cdot 1.5=2.02$ & $\lambda_{u}=\gamma_{f} \cdot \gamma_{m}=1.35 \cdot 1.15=1.55$ \\
ABNT NBR 6118:2014 & $\lambda_{u}=\gamma_{f} \cdot \gamma_{m}=1.4 \cdot 1.4=1.96$ & $\lambda_{u}=\gamma_{f} \cdot \gamma_{m}=1.4 \cdot 1.15=1.61$ \\
\hline
\end{tabular}

\section{NUMERICAL MODELLING}

A two-dimensional (2D) finite element (FE) model of a deep beam with unusual geometry is developed using the commercial software ABAQUS/Standard. This section will describe the experimental test of the deep beam chosen in the bibliography and details of the modelling and constitutive models used for validation.

\subsection{Experimental model description}

The FE model was calibrated based on the experimental tests performed by Vieira (2018). Among the deep beams tested by the author, the specimen VP3 was chosen to be modeled and validated in this paper. Figure 6 shows the details of the test, designed with 3 cutouts distributed asymmetrically to cause discontinuities in the struts and the ties.

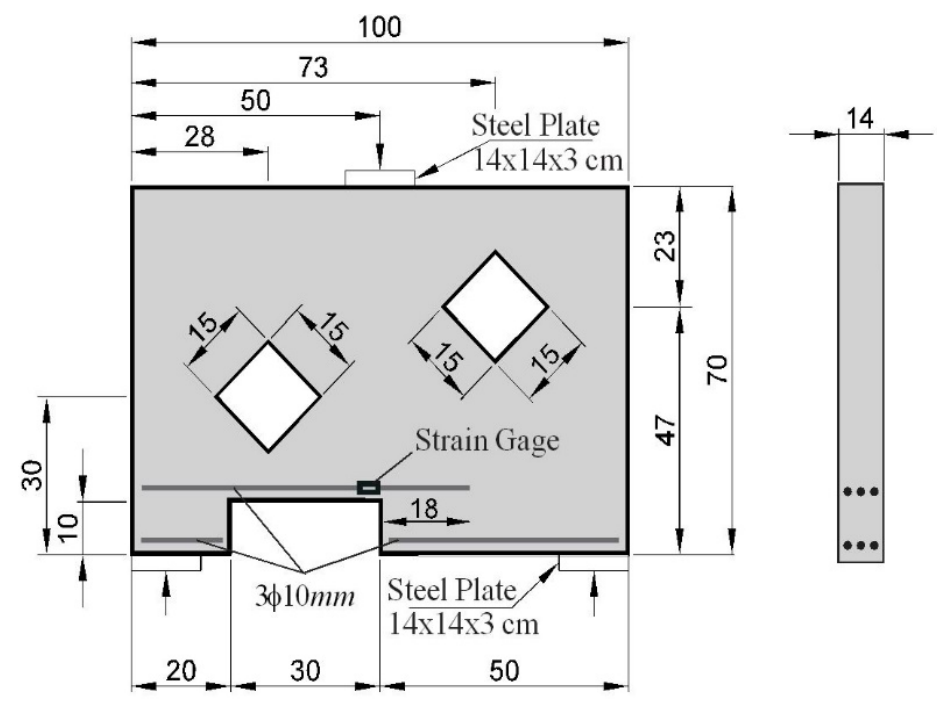

Figure 6: Deep beam geometry, in centimeters (adapted from Vieira, 2018).

The compression strength of concrete was obtained with a simple compression test. A total of 14 cylindrical test specimen with $100 \times 200 \mathrm{~mm}$ were tested, resulting in a mean compressive strength $\left(f_{\mathrm{cm}}\right)$ of $35,58 \mathrm{MPa}$. The steel used was steel of category CA-50 with $10 \mathrm{~mm}$ diameter, elastic modulus $\left(E_{s}\right)$ of $210 \mathrm{GPa}$ and yield stress $\left(f_{y}\right)$ of $550 \mathrm{MPa}$.

\subsection{Finite element model}

All the concrete components of the deep beam are modelled with the four-node bilinear plane stress quadrilateral elements (CPS4) and the steel rebars are modelled with the two-node linear beam elements (B21), both with a size of approximately $10 \mathrm{~mm}$. For the concrete constitutive model, ABAQUS has the Concrete Damaged Plasticity (CDP). The model caters a general capacity for modeling concrete material using concepts of isotropic damaged elasticity in association with isotropic tensile and compressive plasticity to simulate the inelastic behavior of concrete and can be used with rebar to model concrete reinforcement (Analysis User's Guide - ABAQUS 6.14, 2014). 
The CDP is based on the models proposed by Lubliner et al. (1989) and by Lee and Fenves (1998) and considers uniaxial behavior data of the concrete and parameters of plasticity. The uniaxial data are the tensile and compressive stress-strain behavior of the concrete and the five parameters $\psi, \epsilon, \sigma_{b o} / \sigma_{c 0}, K_{c}$ and $\mu$, define the yield surface function, the potential flow and the viscosity of the material. More information about the formulation of the CDP can be seen in the Vol. III - Materials on Analysis User's Guide - ABAQUS 6.14. Table 3 shows the parameters used to define the concrete material.

Table 3: Concrete parameters in ABAQUS.

\begin{tabular}{ccc}
\hline Parameter & Value & Explanation \\
\hline$E_{0}$ & 32194.7 & Elastic modulus (MPa) according to Eurocode 2 (2004) \\
$v$ & 0.2 & Poisson's ratio \\
$\psi$ & 42 & Dilation angle \\
$\in$ & 0.1 & Flow potential eccentricity \\
$\sigma_{b 0} / \sigma_{c 0}$ & 1.16 & The ratio of initial equibiaxial compressive yield stress to initial uniaxial compressive yield stress \\
$K_{c}$ & 0.6667 & The coefficient determining the shape of the deviatoric cross-section \\
$\mu$ & 0.00001 & Viscosity parameter \\
\hline
\end{tabular}

Figure 7 shows the compressive and tensile behavior of concrete. For compression, the linear regime occurs up to $40 \%$ of $f_{c m}$ as recommended by EC2 (2004), then the regime becomes non-linear following the model of Carreira and Chu (1985), with the strain $\varepsilon_{c 1}$ being calculated according to the EC2 (2004). For the tensile behavior, the model of Genikomsou and Polak (2015) was adopted, where it is considered a linear regime until the tensile strength $f_{t}$ and after the peak there is an increase of strain taking into consideration the fracture energy and the average size of the finite element. For this model, the fracture energy used was the Model Code (Fédération Internationale du Béton 2010).

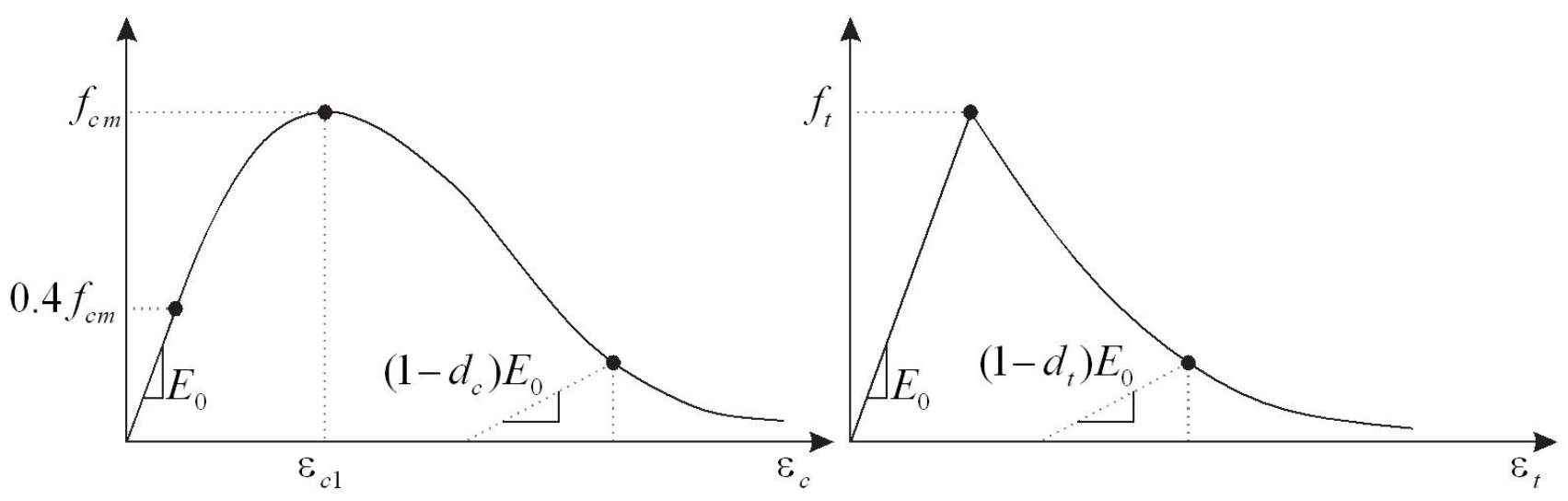

(a)

(b)

Figure 7: Uniaxial compressive and tensile stress-strain relationship for concrete.

The increase of loading level and stress distribution caused damage to the material by reducing the modulus of elasticity controlled by the damage coefficient for compression $\left(d_{c}\right)$ and damage coefficient for traction $\left(d_{t}\right)$, according to Figure 7. The damage models used were Birtel and Mark (2006) for compression and model of Yu et al. (2010) for traction.

For the steel reinforcements, the elastic-perfectly plastic stress-strain material model is adopted. The elastic modulus adopted was $210 \mathrm{GPa}$, yielding stress of $550 \mathrm{MPa}$ and Poisson's ratio of 0.3 . The embedded method was adopted to simulate the bond between the concrete and the reinforcement, assuming perfect bond. The standard incremental and iterative Full-Newton-Raphson method was used in the numerical simulation.

\subsection{Numerical model validation}

To validate the numerical model, the results of the simulation are compared with the experimental results in terms of reinforcement strain above the lower cut, maximum load and cracking pattern. The maximum load of the experimental deep beam was $214 \mathrm{kN}$ and the numerical model of $172 \mathrm{kN}$ (Figure 8), resulting in a difference of $19.6 \%$ due to the 
impossibility of the numerical model to capture auxiliary mechanisms of strength, such as the aggregate interlocking and the dowel action.

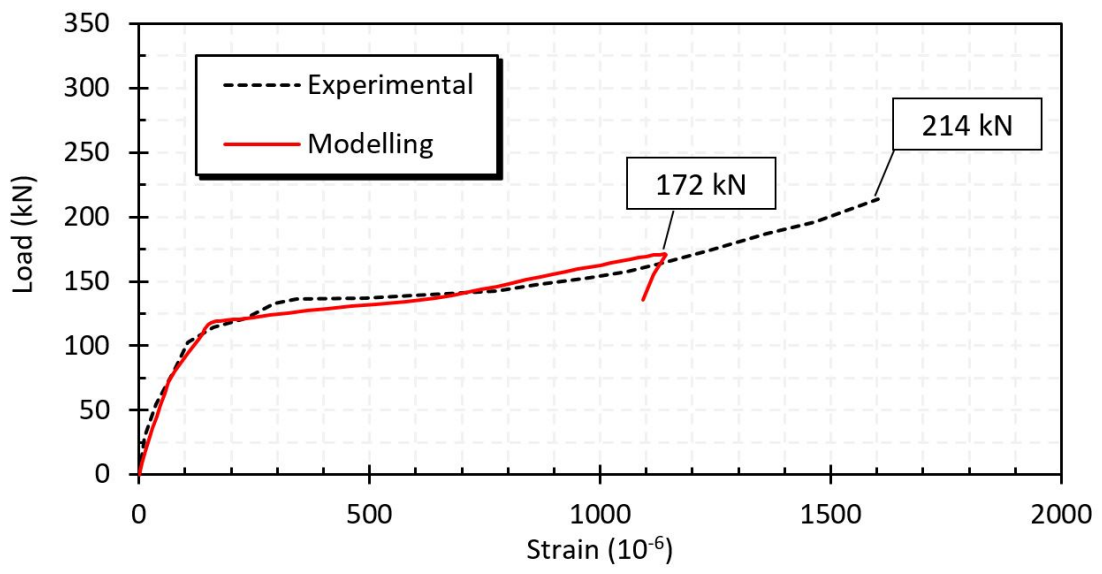

Figure 8: Relationship between load vs strain in reinforcement.

In the experimental test, the formation of cracks occurred in the lower left opening for $136 \mathrm{kN}$ of load (Figure 9). The cracking formation coincides with the decrease in stiffness that can be seen in Figure 8 with the change of slope of the curve, where the reinforcement began to have greater strains.
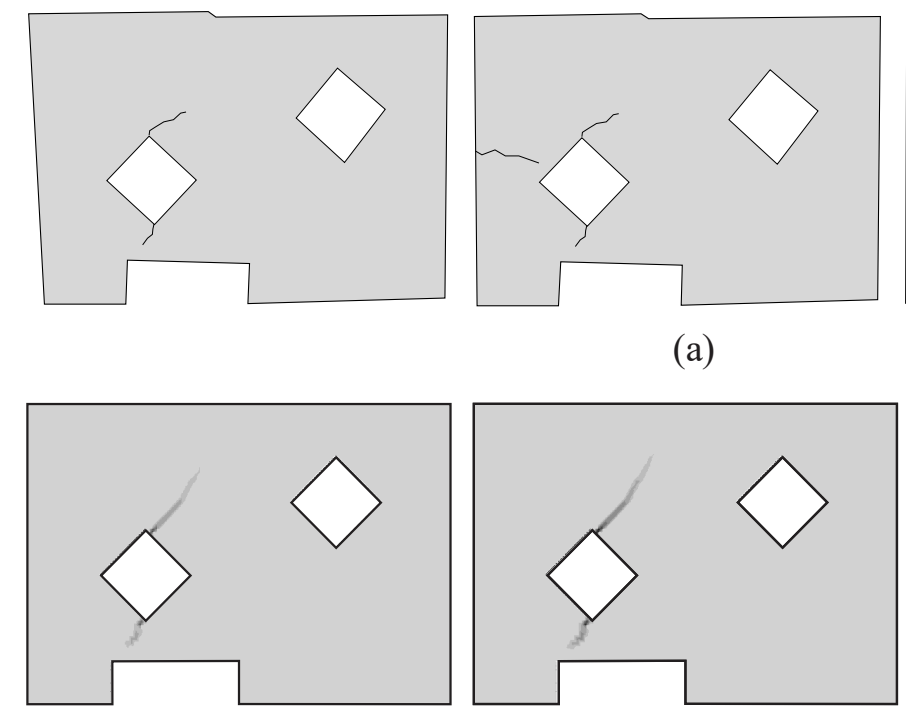

(b)
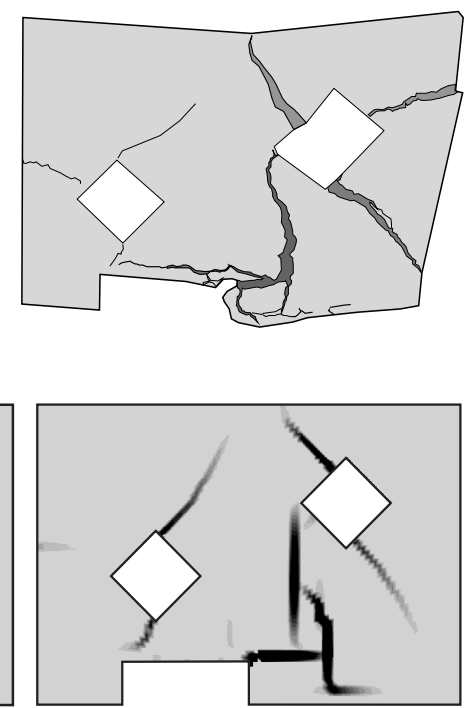

Figure 9: Cracking pattern: a) Experimental deep beam VP3 at $136 \mathrm{kN}, 157 \mathrm{kN}$ and $214 \mathrm{kN}$ loads; b) Numerical models in the loads of $136 \mathrm{kN}, 157 \mathrm{kN}$ and $172 \mathrm{kN}$.

Figure 9 shows the similarity between cracking patterns in both models, starting with small cracks near the lower left hole and brittlely breaking with large cracks on the right side.

\section{STRUCTURAL DETAILING AND SIZING}

\subsection{Analyzed model}

In this paper, all discussions were carried out for the unconventional geometry reinforced concrete deep beam model shown in Figure 10.

The deep beam was loaded with $200 \mathrm{kN} / \mathrm{m}$ and $\gamma_{\mathrm{f}}=1.4$ across the upper face of the structural element. For all the models, the concrete compressive strength is $f_{c k}=35 \mathrm{MPa}$, Poisson ratio is $v=0.20$, and initial elastic modulus is $E_{c i}=32.19 \mathrm{GPa}$. For the reinforcement, the yield strength is $f_{y}=500 \mathrm{MPa}$ and elastic modulus is $E_{s}=210 \mathrm{GPa}$. 


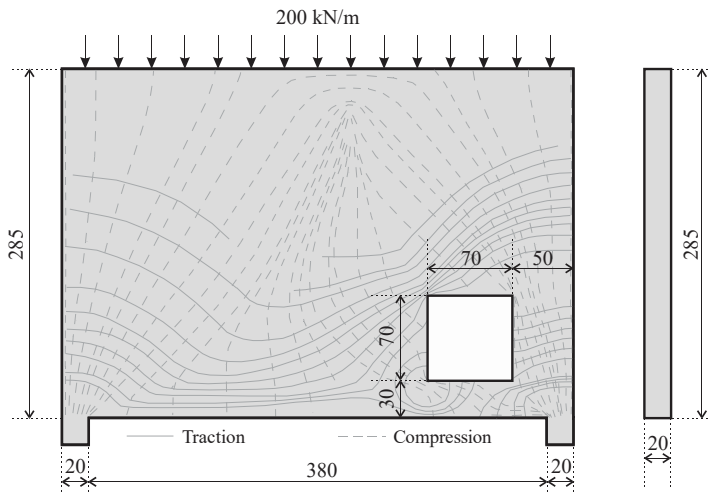

Figure 10: Geometry of the analyzed model and principal stresses trajectories.

\subsection{Design of deep beams based on the STM}

The STM was performed obeying the stress trajectory of the structure obtained through linear numerical analysis using ABAQUS/Standard software. Thus, the field of tensile and compression stresses were observed. Truss bars were added to represent these fields, allowing the design of a representative model in terms of the internal forces in the original structure. However, it was necessary to represent the distributed load as concentrated loads applied to the upper nodes in the same region of the truss, and the load was transferred to the structure through a balance of the nodes.

In this way, four truss models with different discretization were made. The distributed load was divided into 1, 2, 4 and 8 concentrated loads (STM-1, STM-2, STM-4, STM-8), respectively, according to Figure 11.
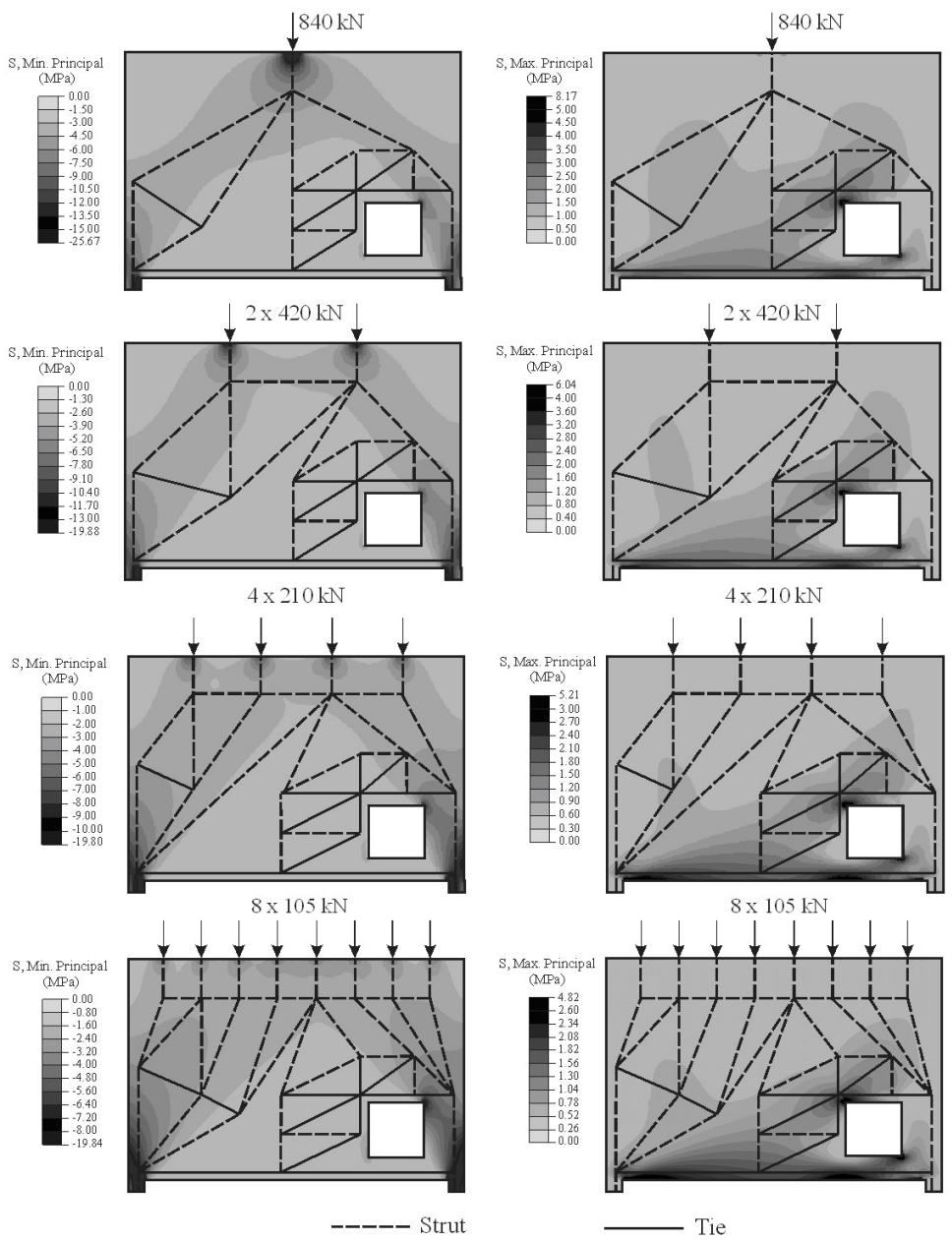

Figure 11: Models STM-1, STM-2, STM-4 and STM-8 on the linear stress distribution. 
All truss models are isostatic and the calculation of STM forces was performed through equilibrium in the nodes. For elements under tension, steel reinforcement was calculated and anchorage verified according to Section 2.1.2. All struts and nodal regions were verified according to Sections 2.1.1 and 2.1.3 and presented satisfactory behavior in relation to concrete strength in the compressed regions.

Sizing zones (Figure 12) were created for the deep beams in order to optimize the distribution of the reinforcement. The design was carried out observing the ties with the greatest stresses in each sizing zone. Thus, the reinforcement distribution considered all tensile regions of the model. Table 4 presents the sizing of all regions in both models, indicating the maximum forces in each zone and the adopted reinforcement.

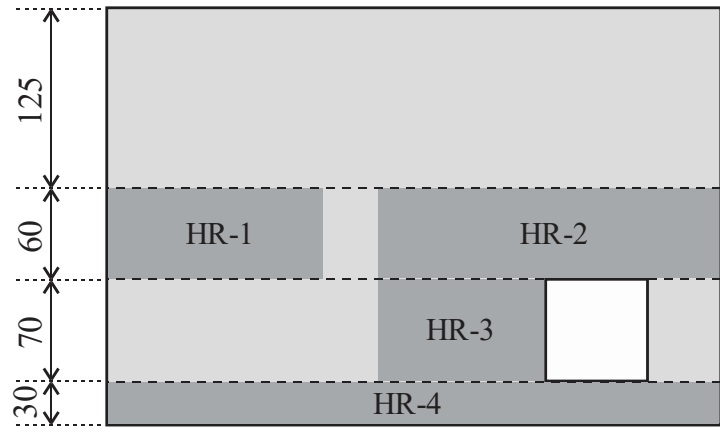

a)

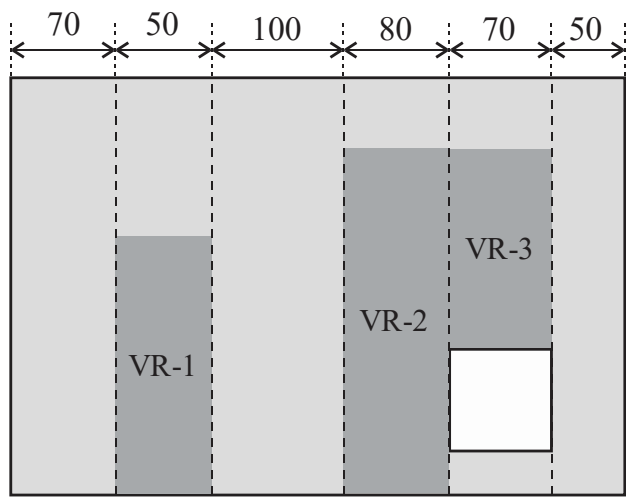

b)

Figure 12: Horizontal and vertical sizing regions.

Table 4: Sizing of traction regions.

\begin{tabular}{|c|c|c|c|c|c|c|c|}
\hline \multicolumn{8}{|c|}{ Maximum forces (kN) } \\
\hline Region & HR - 1 & HR - 2 & HR - 3 & HR - 4 & VR - 1 & VR - 2 & VR - 3 \\
\hline STM-1 & 148.7 & 402.6 & 367.8 & 373.0 & 99.1 & 233.0 & 235.6 \\
\hline STM-2 & 242.6 & 402.6 & 240.0 & 242.6 & 61.6 & 172.2 & 130.4 \\
\hline STM-4 & 92.2 & 394.8 & 223.5 & 223.5 & 33.0 & 111.3 & 102.6 \\
\hline STM-8 & 117.8 & 307.4 & 193.0 & 193.0 & 55.6 & 96.5 & 103.9 \\
\hline \multicolumn{8}{|c|}{ Adopted reinforcement } \\
\hline Region & HR - 1 & HR - 2 & HR - 3 & HR - 4 & VR - 1 & VR - 2 & VR -3 \\
\hline STM-1 & $2 \times 4 \varphi 8.0$ & $2 \times 4 \varphi 12.5$ & $2 \times 6 \varphi 10.0$ & $2 \times 4 \varphi 12.5$ & $2 \times 3 \varphi 8.0$ & $2 \times 4 \varphi 10.0$ & $2 \times 4 \varphi 10.0$ \\
\hline STM-2 & $2 \times 6 \varphi 8.0$ & $2 \times 4 \varphi 12.5$ & $2 \times 6 \varphi 8.0$ & $2 \times 4 \varphi 10.0$ & $2 \times 2 \varphi 8.0$ & $2 \times 4 \varphi 8.0$ & $2 \times 3 \varphi 8.0$ \\
\hline STM-4 & $2 \times 3 \varphi 8.0$ & $2 \times 4 \varphi 12.5$ & $2 \times 5 \varphi 8.0$ & $2 \times 4 \varphi 10.0$ & $2 \times 2 \varphi 6.3$ & $2 \times 3 \varphi 8.0$ & $2 \times 3 \varphi 8.0$ \\
\hline STM-8 & $2 \times 3 \varphi 8.0$ & $2 \times 3 \varphi 12.5$ & $2 \times 5 \varphi 8.0$ & $2 \times 3 \varphi 10.0$ & $2 \times 2 \varphi 6.3$ & $2 \times 4 \varphi 6.3$ & $2 \times 4 \varphi 6.3$ \\
\hline
\end{tabular}

\subsection{Analysis from plane stress - FEM Implementation}

In this paper, a Python algorithm was implemented using the plane stress from a linear elastic analysis in finite elements, applying the sizing and verification criteria of the EC2 (2004).

The difficulties in using Annex F of EC2 (2004) also concern the sampling of elements that will serve as the basis for the verifications and sizing. In this step, points with changes or reentrances in the geometry and regions of direct application of the load were avoided, due to the stress concentrations that can cause high reinforcement ratio, typically unusual to the structural element analyzed.

The reinforcement calculation for all finite element was counterproductive due to the disparity of the steel area required for each FE. Therefore, for a rational sizing the concept of sample rate was defined, that is the ratio between the number of finite elements chosen for the reinforcement calculation and the number of model elements.

In this way, spaced points were selected following the pattern shown in Figure 13. The sample rate has been increased until there was no significant change in the calculated reinforcement areas. With this approach it was possible to define that sample rates higher than $3.5 \%$ did not present a significant increase of the reinforcement. 


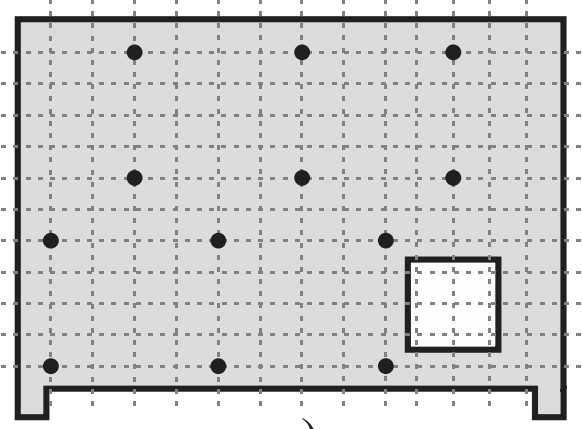

a)

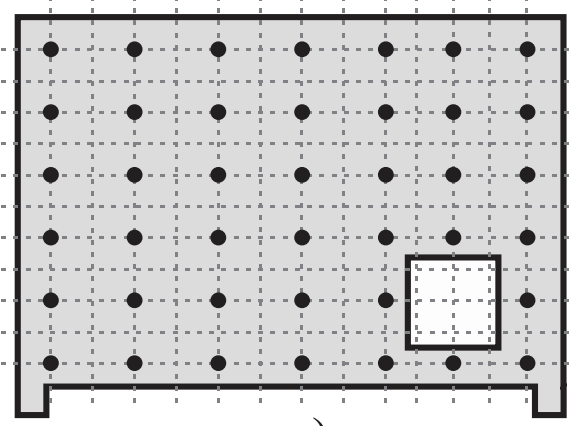

c)

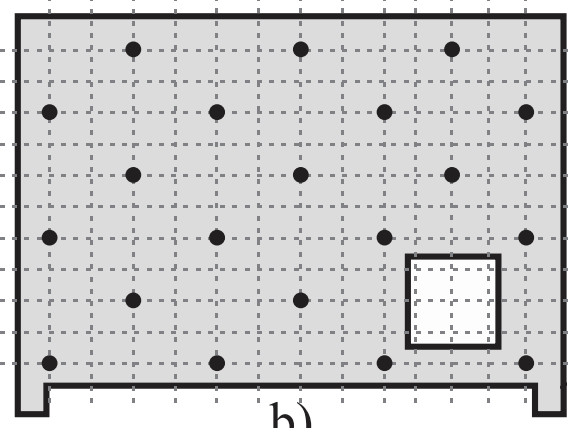

b)

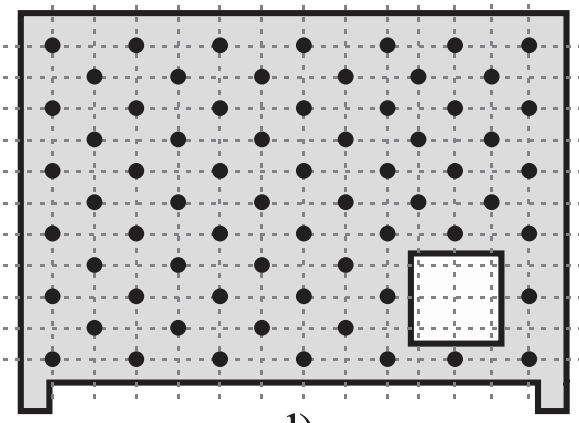

d)

Figure 13: Sample rates of finite elements for sizing: (a) $1.0 \%$, (b) $2.0 \%$, (c) $3.5 \%$, (d) $6.0 \%$.

Thus, because it is a method with sparse use, the authors suggest the following steps for their application:

1. Linear elastic analysis in FE of the structural element.

2. Test of mesh convergence in the finite element model.

3. Sampling of points in the FE model for reinforcement sizing and verification of concrete according to the following criteria:
a. Avoid points of singularity (stress concentration).
b. Select sequentially spaced points.
c. Check variations in the reinforcement ratio with the increase in the number of points sampled.

\subsection{Reinforcement detailing}

After the sizing of the models, the reinforcement distributions were proposed according to Figure 14. The detailing provided adequate safety and ensured good ductility conditions for the structural elements. In order to compare the obtained results, the minimum reinforcements recommended by the standards were not applied, but only those calculated for the internal forces. 


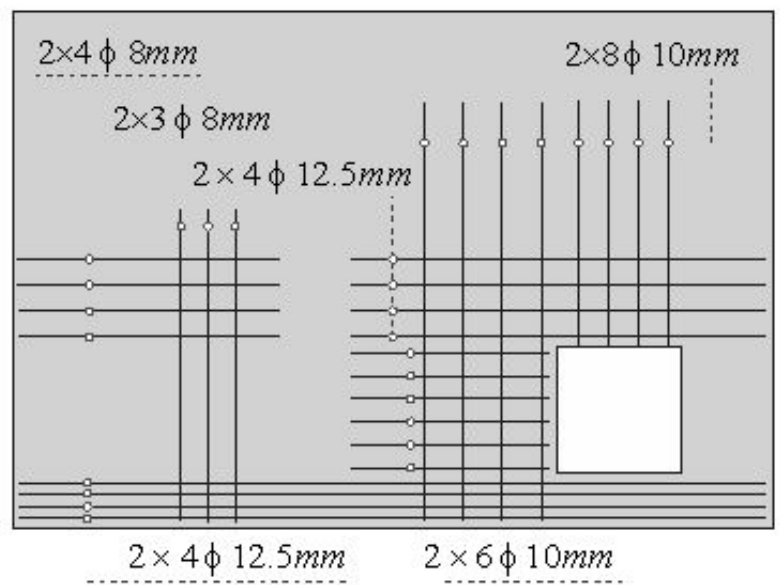

a)

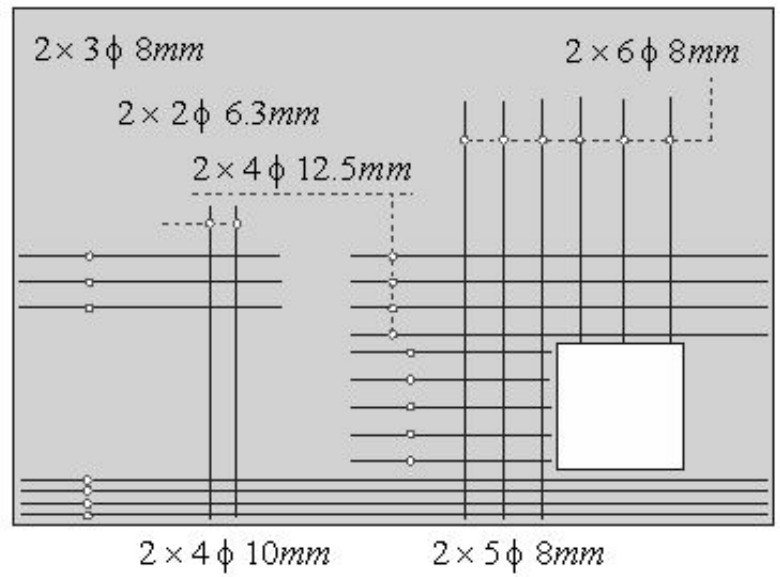

c)

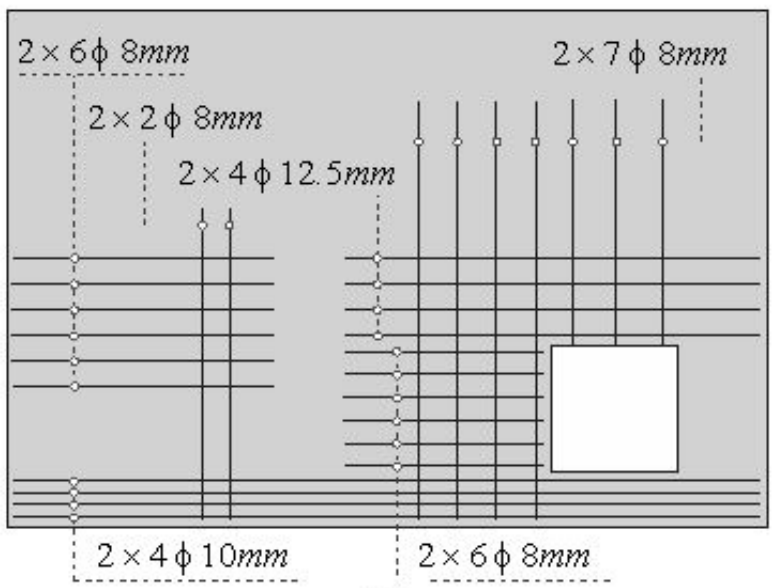

b)

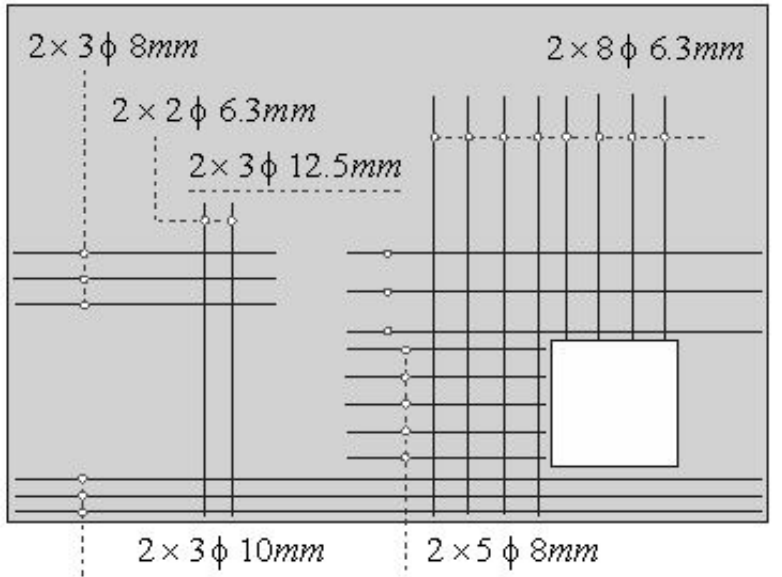

d)

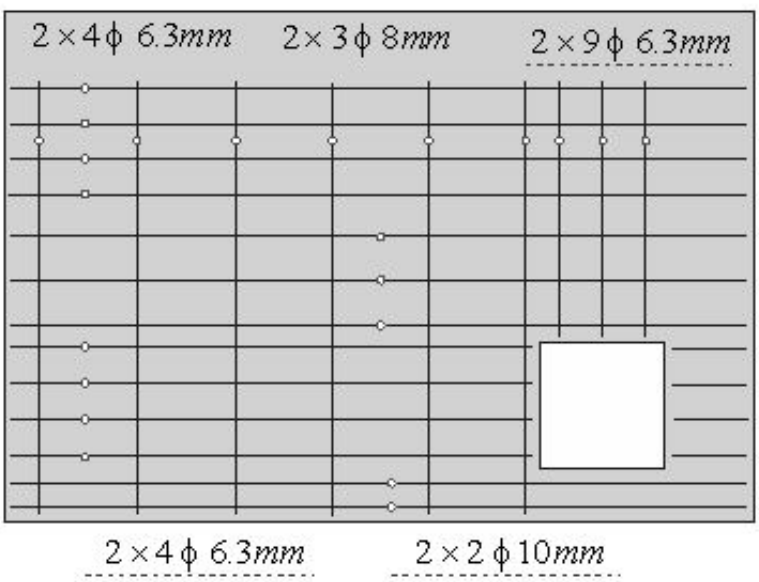

e)

Figure 14: Detailing the models: (a) STM-1, (b) STM-2, (c) STM-4, (d) STM-8 and (e) SFM.

The divergence between the reinforcement detailing is explained by the calculation method adopted. The models sized through the STM presented an arrangement of reinforcements according to the sizing zones indicated in Section 4.2. However, the SFM model assumed a continuous reinforcement distribution due to the plane stress adopted in its design. The anchoring was assured by the presence of fasteners that allowed the stress transfer from the reinforcement to the concrete. 


\section{NONLINEAR FINITE ELEMENT ANALYSIS}

The nonlinear analysis performed in this paper aims to evaluate the behavior of the structures previously discussed in both service and rupture. The 2D models were developed using commercial software ABAQUS/Standard, according to the recommendations and validation described in Section 3, and discretized in 7668 four node bilinear plane stress quadrilateral, with a size of approximately $40 \times 40 \mathrm{~mm}$. The characteristics of the materials and the structural element followed the geometry and the boundary conditions presented in the previous section. Figure 15 presents information on the numerical model, mesh and finite element types used in the analysis.

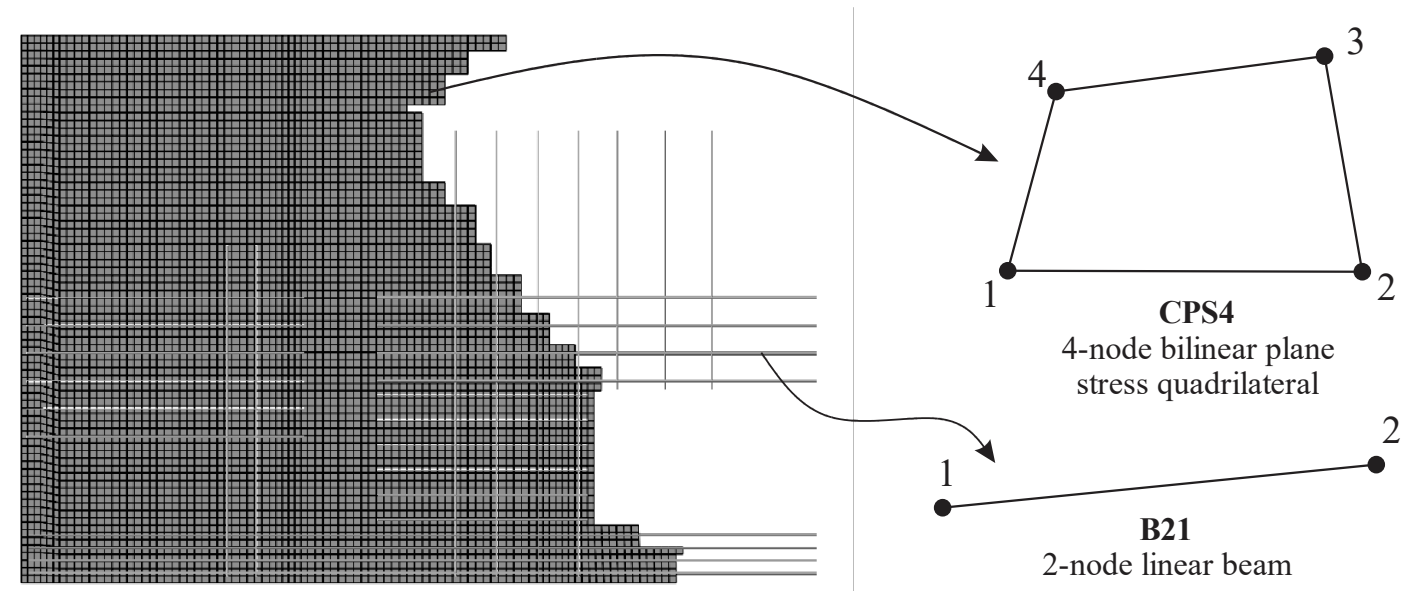

Figure 15: Finite element model.

As the behavior of the post-peak structural element is not necessary in the context of this analysis, and it is necessary to know the maximum load in terms of distributed load, the numerical analysis was performed using load control within the criterion of numerical stability of the Full-Newton-Raphson method, used to solve the nonlinear problem.

A uniformly distributed load of $800 \mathrm{kN} / \mathrm{m}$, four times higher than that used in the design, was applied to the drawing of the curves shown in Figure 16. Next, the numerical results are presented in terms of the load capacity, strains and the cracking pattern developed in each model.

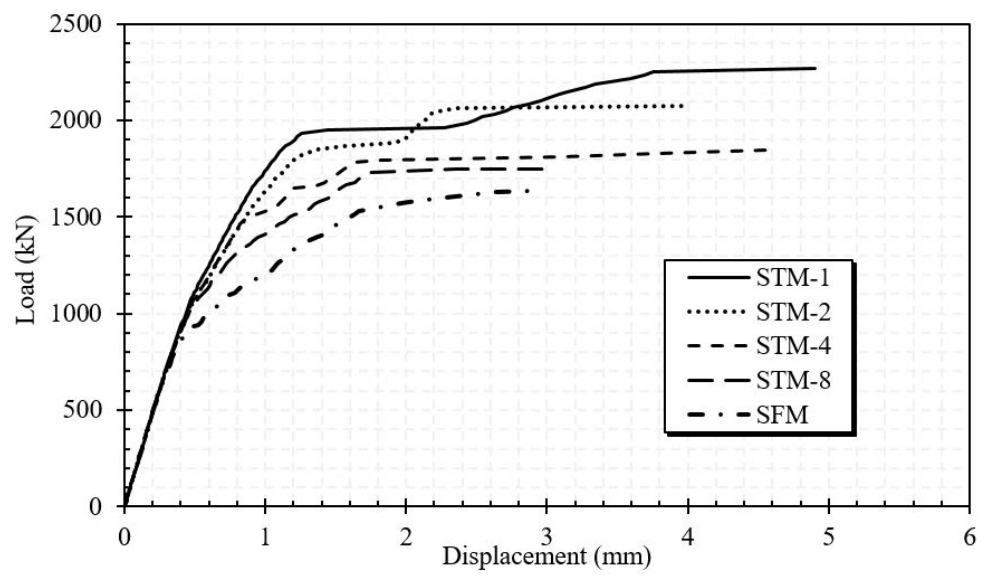

Figure 16: Results of the numerical test - displacement in the middle of the span.

The results of Figure 16 show that all the models evaluated presented a linear behavior for the project defined load $(840 \mathrm{kN})$, demonstrating that the serviceability limit state related to the formation of cracks and excessive strains are satisfied for all the calculation approaches.

The large displacements observed in Figure 16 for the models calculated by the STM were related to an abrupt development of the cracking. In the STM-1 model, this cracking preceded the yield of the reinforcement, and was the result of the rapid progression of a crack in a region without reinforcement. In the STM-2, STM- 4 and STM- 8 models the beginning of the large displacements coincided with the yielding of the reinforcements, which caused a substantial cracking of the deep beam. In SFM, this large displacement was not characterized due to the layered arrangement of the 
reinforcement, allowing the yielding of each layer to precede that of the previous one leading to a loss of gradual stiffness until rupture.

The cracking patterns found in each of the models were related to the adopted calculation approach, with the difference between the models sized by the STM in relation to the EC2 (2004). Figure 17 shows the magnitude of the plastic strains that represent the cracking patterns.
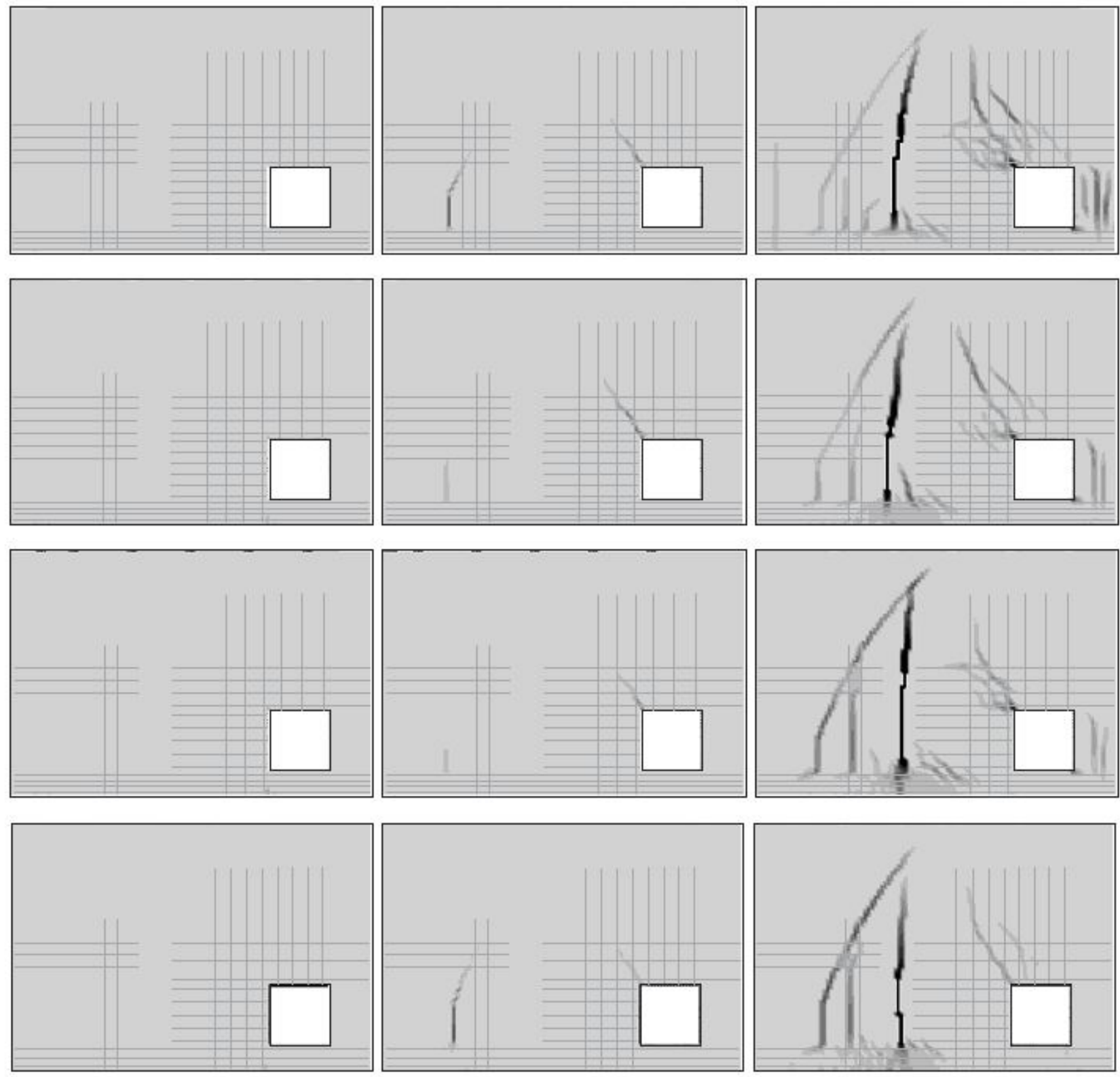

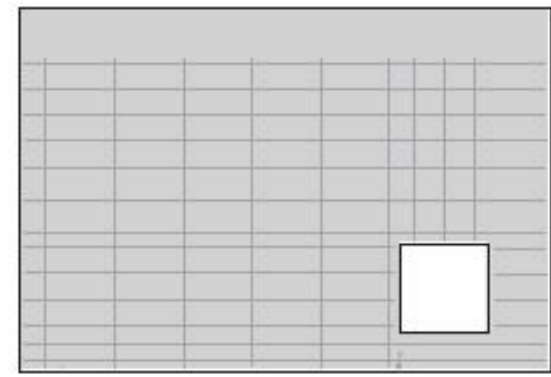

(a)

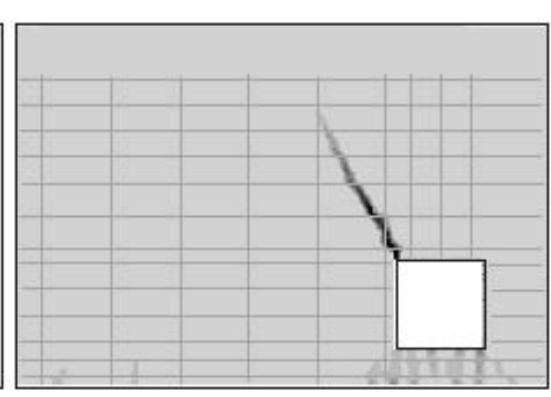

(b)

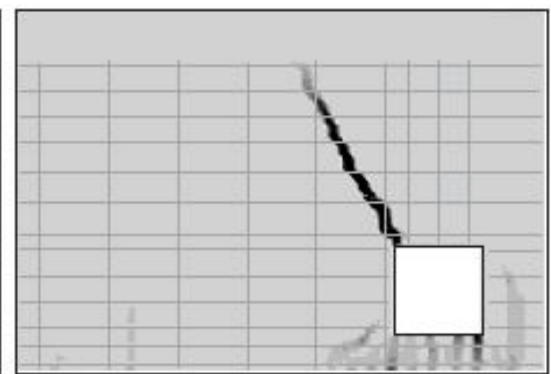

(c)

Figure 17: Cracking pattern for (a) $F_{d}$ (b) $0.8 F_{u}$ and (c) $F_{u}$, of STM-1, STM-2, STM-4, STM-8 and SFM, respectively. 
Figure 17 illustrates the cracking patterns for three loading conditions: at the design load $\left(F_{d}\right)$, at $80 \%$ of maximum load $\left(0.8 F_{u}\right)$ and at the maximum load $\left(F_{u}\right)$, making it possible to evaluate the progress of the patterns at different stages of the analysis. The cracks developed in the STM tests occurred more distributed throughout the model due the nonreinforced regions (Figure 12). Furthermore, the plastic strain for $0.8 F_{u}$ in the STM were at least 52\% lower than SFM due the higher reinforcement ratio in stress concentration regions.

\section{DISCUSSION}

As discussed in Section 2.4, the factor of safety required for the evaluation of structural integrity from a nonlinear analysis varies according to the material in which the rupture has developed. For the structural elements analyzed, it was possible to verify a systematic yield of the reinforcement, that intensified the damage in the concrete leading to the failure.

Table 5: Factor of Safety.

\begin{tabular}{ccc}
\hline & Maximum Load & Factor of Safety $\left(\lambda_{u}\right)$ \\
\hline STM-1 & $2268.0 \mathrm{kN}$ & 3.78 \\
STM-2 & $2078.5 \mathrm{kN}$ & 3.46 \\
STM-4 & $1848.0 \mathrm{kN}$ & 3.08 \\
STM-8 & $1750.7 \mathrm{kN}$ & 2.92 \\
SFM & $1635.8 \mathrm{kN}$ & 2.73 \\
\hline
\end{tabular}

Thus, as the rupture was characterized by the yielding of steel, the greatest safety factor that the deep beams should be is $\lambda_{u}=1.65$ calculated from the propositions of the Canadian Standards Association (2004). The safety was demonstrated for all models as indicated in Table 5, then it is necessary to evaluate the performance conducted in their design.

The energy associated with the stretching of all ties was calculated from the strain of the rebars used in each model (Figure 14) that were obtained from the nonlinear analysis. As the length of the rebars was the same for all STM, the force and strain were the critical parameters in the minimum energy strain calculation. Thus, this metric is associated to the relation between the maximum load and the deformability of the structural element. The results of this metric are summarized in Table 6.

Table 6: Energy associated with the models.

\begin{tabular}{cc}
\hline Model & $\sum F_{i} \cdot l_{i} \cdot \varepsilon_{i}$ \\
\hline STM-1 & 1759.2 N.m \\
STM-2 & 480.7 N.m \\
STM-4 & 335.2 N.m \\
STM-8 & 353.2 N.m \\
SFM & 359.6 N.m \\
\hline
\end{tabular}

The SFM obtained an inferior performance compared to the STM- 4 and STM- 8 in the minimum energy strain criterion as a result of the greater ties length of the adopted detailing. Therefore, it was verified that although all the models are presented in safety condition, it is possible to have solutions with an optimized mechanical behavior insofar as the load discretization is evenly distributed.

As safety conditions are assured, other assessments for the determination of the method of analysis and design should be included. Therefore, steel usage and its efficiency, which are important for the socio-environmental and economic evaluations, were studied. In this sense, the efficiency is defined as the ratio between the maximum load and the steel rate employed in each model, having the unit of kN/kg. The results of this last metric can be found in Figure 18. 


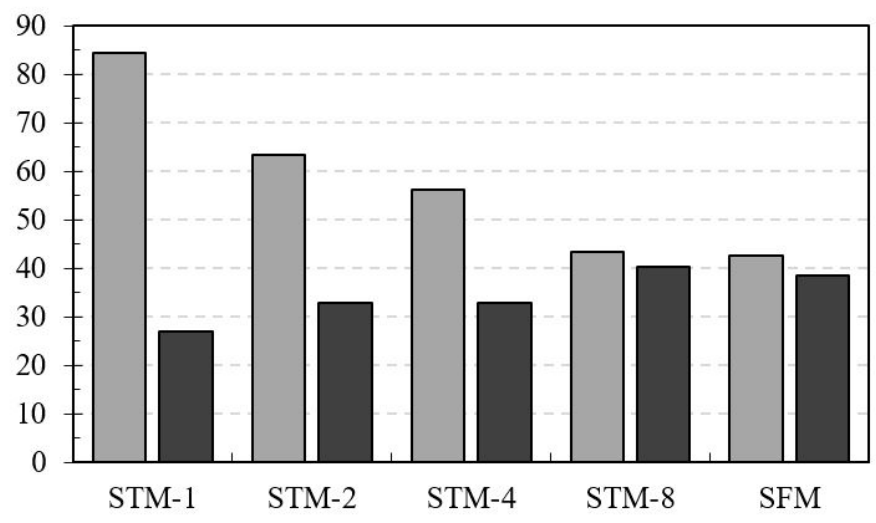

Figure 18: Consumption and efficiency of the analyzed models.

\section{CONCLUSIONS}

The present study focused on developing of numerical analysis to investigate the deep beams behavior in reinforced concrete. The beams were evaluated from strut and tie model for different design solutions by four load discretizations. In addition, this research presented another solution for the design of deep beams from the in-plane stress conditions. The models were compared through different performance metrics and the rupture conditions were predicted by a nonlinear analysis in FEM.

- Concerning the structural behavior, it is verified that regardless of the adopted method, the Serviceability Limit State were met for strain and cracking. In this way, the choice for a calculation model will be based on the required security and performance metrics discussed in this paper.

- The cracking pattern is also a parameter in the choice of analysis method. The application of FEM leads to a solution with less propagation of cracks, although the larger crack opening found in this model is larger than those developed in STM. These two characteristics are related to the reinforcement arrangement for each model. While the SFM conforms to a uniformly distributed reinforcement, the STM concentrates the bars in the directions of the greatest tensile stress.

- $\quad$ All the analyzed solutions resulted in structures that satisfy the Ultimate Limit State. It was observed that the deep beam STM-1 presented a load capacity of up to $38.6 \%$ higher in relation to the other models. In contrast, the results indicate that this model, with lower discretization of loading, have a less structural efficiency. Therefore, the adoption of this simplification should not precede the evaluation of optimization and efficiency criterion.

- The strain energy of the reinforcements has been shown to be inversely proportional to the safety factor. Thus, struts and ties models that consider a greater discretization of load constitute more rational structural solutions from the energy point of view, but presenting a lower safety factor. However, the safety factors were, respectively, $3.78,3.46,3.08,2.92$ and 2.78 for the deep beams STM-1, STM-2, STM-4, STM-8 and SFM, so all evaluated models remained above acceptable limits.

- In agreement with the minimum energy criterion, the consumption data and efficiency of each model indicated that the solutions of better load discretization lead to more efficient and economic structures. The rate reinforcement was substantially reduced due to the load conditions. In relation to STM-1, the reduction was $25 \%, 33.3 \%, 49.6 \%$ and $47.5 \%$ for the deep beams STM-2, SM-4, STM-8 and SFM, respectively. However, despite the reduction in the reinforcement rate, the structural efficiency increased systematically $21.9 \%, 22.3 \%, 49.8 \%$ and $43.1 \%$ for the same models, respectively.

- The solution from a finite element model is also highlighted, because although it results in a lower factor of safety, it was large enough to attest to structural safety. Moreover, from this model the highest economic efficiency was achieved.

Based on this study, the proposed solutions for different loading conditions are valuable tool for the development of consistent deep beams design. Furthermore, the authors emphasize the efficiency of the analysis through in-plane stress conditions and the importance of more investigations on the application of the method in the analysis of 2D elements in discontinuous regions. 


\section{ACKNOWLEDGEMENTS}

This study was financed in part by the Coordenação de Aperfeiçoamento de Pessoal de Nível Superior - Brasil (CAPES) - Finance Code 001, and by the National Council for Scientific and Technological Development (CNPq).

Author's Contributions: Conceptualization, DP Santos, JAD Fernandes Neto and L Reginato; Methodology, DP Santos, JAD Fernandes Neto and L Reginato; Formal analysis, DP Santos, JAD Fernandes Neto and L Reginato; Investigation, DP Santos, JAD Fernandes Neto and L Reginato; Writing - original draft, DP Santos, JAD Fernandes Neto and L Reginato; Writing - review \& editing, DP Santos, JAD Fernandes Neto, L Reginato and R Carrazedo; Supervision, R Carrazedo.

Editor: Pablo Andrés Muñoz Rojas.

\section{REFERENCES}

ABAQUS 6.14. (2014). Abaqus Analysis User's Guide (6.14), DS Simulia.

Almeida, V. S., Simonetti, H. L., \& Neto, L. O. (2013). Comparative analysis of strut-and-tie models using Smooth Evolutionary Structural Optimization. Engineering Structures, 56, 1665-1675.

American Concrete Institute. (2014). Building Code Requirements for Structural Concrete (ACl 318-14): Commentary on Building Code Requirements for Structural Concrete (ACI 318R-14): an ACI Report. American Concrete Institute. ACl.

Associação Brasileira De Normas Técnicas. (2014). NBR 6118:2014 - Projeto de Estruturas de Concreto - Procedimento, Rio de Janeiro, Brazil.

Birtel, V., and Mark, P. (2006). Parameterised finite element modelling of RC beam shear failure. In ABAQUS users' conference (pp. 95-108).

Blaauwendraad J. (2010). Plates and FEM surprised and Pitfalls. Solid Mechanics and it's applications. Volume 171, TU Delft, The Netherlands.

British Standards Institution. (2004). Eurocode 2: Design of concrete structures: Part 1-1: General rules and rules for buildings. British Standards Institution.

Canadian Standards Association. (2004). Design of concrete structures. Mississauga, Ont.: Canadian Standards Association.

Carreira, D. J., and Chu, K. H. (1985). Stress-strain relationship for plain concrete in compression. Journal Proceedings, Vol. 82, No. 6, pp. 797-804.

Dhahir, M. K. (2018). Strut and tie modeling of deep beams shear strengthened with FRP laminates. Composite Structures, 193, 247-259.

El-Sayed, A. K. (2014). Strut and tie modeling for RC short beams with corroded stirrups. Latin American Journal of Solids and Structures, 11(12), 2255-2270.

Fédération Internationale du Béton. (2010). Model Code 2010 - First Complete Draft. fib Bulletin, n. 55, p. 318.

Genikomsou, A. S., and Polak, M. A. (2015). Finite element analysis of punching shear of concrete slabs using damaged plasticity model in ABAQUS. Engineering Structures, 98, 38-48.

Hardjasaputra, H. (2015). Evolutionary structural optimization as tool in finding strut-and-tie-models for designing reinforced concrete deep beam. Procedia Engineering, 125, 995-1000.

Hawileh, R. A., El-Maaddawy, T. A., \& Naser, M. Z. (2012). Nonlinear finite element modeling of concrete deep beams with openings strengthened with externally-bonded composites. Materials \& Design, 42, 378-387.

Herranz, U. P., María, H. S., Gutiérrez, S., and Riddell, R. (2012). Optimal Strut-and-Tie Models Using Full Homogenization Optimization Method. ACI Structural Journal, 109(5).

Hussain, Q., and Pimanmas, A. (2016). Shear strengthening of RC deep beams with sprayed fibre-reinforced polymer composites (SFRP) and anchoring systems: part 1. Experimental study. European Journal of Environmental and Civil Engineering, 20(1), 79-107. 
Ibrahim, M. A., El Thakeb, A., Mostfa, A. A., and Kottb, H. A. (2018). Proposed formula for design of deep beams with shear openings. HBRC Journal, $14(3), 450-465$.

Kim, B. H., and Yun, Y. M. (2011). An Indeterminate Strut-Tie Model and Load Distribution Ratio for RC Deep Beams-(I) Model \& Load Distribution Ratio. Advances in Structural Engineering, 14(6), 1031-1041.

Lee, J., and Fenves, G. L. (1998). Plastic-damage model for cyclic loading of concrete structures. Journal of engineering mechanics, 124(8), 892-900.

Liang, Q. Q., Xie, Y. M., and Steven, G. P. (2000). Topology optimization of strut-and-tie models in reinforced concrete structures using an evolutionary procedure. ACI Structural Journal, 97(2).

Lim, E., and Hwang, S. J. (2016). Modeling of the strut-and-tie parameters of deep beams for shear strength prediction. Engineering Structures, 108, 104-112.

Lubliner, J., Oliver, J., Oller, S., and Oñate, E. (1989). A plastic-damage model for concrete. International Journal of solids and structures, 25(3), 299-326.

Marti, P. (1985). Basic tools of reinforced concrete beam design. In Journal Proceedings (Vol. 82, No. 1, pp. 46-56).

Mello, A. F. A. D., and Souza, R. A. D. (2016). Analysis and Design of Reinforced Concrete Deep Beams by a Manual Approach of Stringer-Panel Method. Latin American Journal of Solids and Structures, 13(6), 1126-1151.

Moradi, M., and Esfahani, M. R. (2017). Application of the strut-and-tie method for steel fiber reinforced concrete deep beams. Construction and Building Materials, 131, 423-437.

Najafian, H. A., and Vollum, R. L. (2013). Design of planar reinforced concrete D regions with nonlinear finite element analysis. Engineering Structures, 51, 211-225.

Pimentel, M. J. D. S. (2004). Modelação e análise de estruturas laminares de betão: Possibilidades e desafios, Master's Dissertation, Universidade do Porto, Portugal.

Qazi, S., Michel, L., Ferrier, E., and Limam, A. (2015). Strut-and-tie model for a reinforced concrete wall strengthened with carbon fibre-reinforced polymers. Composite Structures, 128, 87-99.

Schlaich, J., Schäfer, K., and Jennewein, M. (1987). Toward a consistent design of structural concrete. PCI journal, 32(3), 74150.

Silva, R. C. D., \& Giongo, J. S. (2000). Modelos de bielas e tirantes aplicados a estruturas de concreto armado, Projeto REENGE EESC - USP (Brazil).

Souza, R. A., and Bittencourt, T. N. (2006). Análise, dimensionamento e verificaçao de elementos especiais em concreto armado utilizando o método dos elementos finitos e o método das bielas. Revista Internacional de Métodos Numéricos para Cálculo y Diseño en Ingeniería, 22(1), 31-44.

Vieira, A. A. (2018). Análise Experimental e Numérica de Vigas Parede com Geometrias Não Convencionais de Concreto Armado. Ph.D. Thesis, University of Brasilia, Brazil.

Yu, T., Teng, J. G., Wong, Y. L., and Dong, S. L. (2010). Finite element modeling of confined concrete-I: Drucker-Prager type plasticity model. Engineering Structures, 32(3), 665-679.

Zhong, J. T., Wang, L., Deng, P., and Zhou, M. (2017). A new evaluation procedure for the strut-and-tie models of the disturbed regions of reinforced concrete structures. Engineering Structures, 148, 660-672. 